\title{
Factors Influencing Conception Rate of Local and Crossbred Cows
}

\author{
Dr.Vinod V Potdar ${ }^{1}$, Dr.KaustubhBhave ${ }^{2}$, Mr.Yuvraj Gaundare ${ }^{3}$, \\ Dr.Hitesh.R.Awasthi ${ }^{4}$, Dr.Jayant.R.Khadse ${ }^{5}$ \\ BAIF Central Research Station, Uruli Kanchan, Pune 412202
}

\begin{abstract}
A study was conducted for a period of 5 years at various cattle development centres in Maharashtra to evaluate the effects of genetic and environmental factors on conception rate with 28274 cows of five breeds. The experimental animals were within zero to 4th parity and they were inseminated artificially through using the semen from different sires. The overall feeding and management of the animals was almost similarly kept by the farmers. From this study, it was observed that conception rate of the cows was significantly affected by cattle breed, sire breed, heat stage, AI number, lactation number while there was no significant difference due to body condition of animal.

It was concluded that the factors like cattle breed, lactation number, AI number, sire breed are the most important factors to get maximum conception rate of the cows.
\end{abstract}

Key Words: Cow; Conception rate; Artificial Insemination

\section{Introduction}

Agriculture is the backbone of Indian economy and livestock is an integral part of agriculture, which plays a pivotal role in providing employment to unemployed youth. It provide subsidiary income source not only to the marginal and small farmer but also the poor and weaker section of the society and significantly contributing their health and nutrition who live in rural area of the country. India has the largest livestock populations in the world. It ranks first in respect of cattle population in the world but producing only 14 percent of world milk production. The milk production is totally depends upon the reproductive performance of cow. Increased milk production demands have led to a decline in the reproductive performance of the dairy cows.

The high reproductive performance is a key factor for optimal economic success in cattle production. No dairy production system is sustainable without an acceptable level of reproduction. The main reproductive factors responsible for economic losses to dairy farmer are delayed puberty and sexual maturity, low conception rate, long calving interval, prolonged post-partum anestrous and short productive life.AI program always demands to keep records of non-return rate, conception rate, service per conception and calving rate in order to properly evaluate the reproductive efficiency of cows, skill-ness of the inseminators, fertility and semen quality of bulls. However, an effective reproductive recording system must provide the cattle owner with the key information required to make reproductive management decision. Ideally, optimum economic fertility could be achieved with a pregnancy rate of $80 \%$ after the first insemination, a maximum of 1.3 services per conception and an average interval of 85 days between parturition and conception (Morrow, 1980).

Conception rate is directly associated with the production attribute and responsible for monitoring life time productivity of the individual animal. Conception is the first pre-requisite of an animal entering into the productive life.

Conception rate determines directly to the total profitability of farm enterprises. Thus, to achieve the maximum profitability, it is very important to increase the conception rate up to maximum level. On the contrary, there are many genetic and non-genetic factors, viz. breeds of cow, breed of bull, age and parity of cow, semen quality, season etc., have direct influence on increasing conception rate.

Considering these, the present study was planned with the aim to evaluate the effects of genetic, environmental and their interactions affecting conception rate in cattle and to recommend an optimum approach for achieving maximum conception rate in cattle.

\section{Materials And Methods}

The study was conducted at cattle development centres across Maharashtra for a period of June 2010 to June 2015 with 12117 cows and 16157 heifers of five different breeds. The animals were within zero to fourth

\footnotetext{
${ }^{1}$ Dr.Vinod V Potdar(First Author) Genetics Department, Central Research Station, BAIF

${ }^{2}$ Dr.Kaustubh G Bhave (Second Author) Genetics Department, Central Research Station,BAIF

${ }^{3}$ Mr.Yuvraj S Gaundare (Second Author) Genetics Department, Central Research Station,BAIF

${ }^{4}$ Dr.Hitesh.R.AwasthiAdditional ACPE,BAIF

${ }^{5}$ Dr.Jayant.R.Khadse Research Director, Central Research Station,BAIF

DOI: $10.9790 / 2380-0910015154 \quad$ www.iosrjournals.org $\quad 51 \mid$ Page
}


parity. Most of the animals were indigenous non-descript local cattle and crossbreds. The overall feeding and management of the animals was almost similar and these are kept by the farmers with stall feeding and grazing.

The animals were fed mainly rice straw as a staple feed with seasonal green grass depending on the availability. Wheat bran, oil cake, rice polish etc. were supplied as concentrate feed to the cows on optional basis.

Semen from central research station was delivered to different cattle development centres. When the farmers brought their animals to the AI center, the reproductive status and estrus condition of the animals were checked and determined by observing the clinical signs artificial insemination was done after a variable period of signs of estrus, ranging from $8 \mathrm{~h}$ to $24 \mathrm{~h}$, by trained AI technician with thawed semen straw.

To determine the first service per conception rate, the pregnancy diagnosis was done between 60 to 90 days after insemination by rectal palpation (Ball, 1980) at the farmer's house. Then first service conception rate for particular group was determined by the number of heifers or cows given first service multiplied by 100 .

No. of cows pregnant

Conception rate $(\mathrm{CR})=$

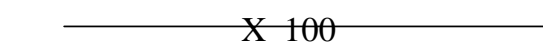

No. of cows inseminated

To determine the conception rate of the animals, the parameters (breed of cows, parity of cows, sire breed, heat stage, body condition, AI sequence number, season of insemination) were studied and data on the various variable were analyzed under the least squares procedure in $r$ statistical package.

\section{Results And Discussion}

To evaluate the effect of genetic, environmental factors and their interaction on conception rate in cows, the results of the study are discussed below.

\section{Effect of cattle breed}

Cattle breed has significant effect over conception rate. Highest $(49.17 \%)$ conception rate (CR) was observed in dangi breed of cows and lowest $(41.36 \%)$ in Holstein Friesian there was significant $(\mathrm{P}>0.05)$ difference in conception rate among the different breeds of cows (Fig. 1). Rao et al. (1992) observed higher CR of indigenous cows than other genotypic groups. Besides this, Marongiu et al. (2002) reported that CR was significantly $(\mathrm{P}<0.01)$ higher in Sarda cows $(95 \%)$ than Charolasis $\times$ Sarda cows $(57 \%)$. In practices, it is difficult to find out the effect of cattle breed on their fertility. Environmental and management conditions those might have more influence on fertility.

\section{Effect of sire breed}

In this study, it was observed that there was sire breed has significant $(\mathrm{P}<0.05)$ difference over conception rate (Fig. 2). Finland Central Association of AI societies (1978) found difference in conception rate of cows for various breeds of bull.

\section{Effect of parity of cows}

In this experiment, the first service conception rate was studied from zero to 5 th parity. The conception rate (CR) was higher in heifers than in other parity and then decreased up to last parity. It was observed that the $\mathrm{CR}$ in 2nd,3rd and 4th parity differed significantly $(\mathrm{P}<0.05)$. The steady decline of the CR may be clearly observed (Fig. 3). Bhagat and Gokhale (1999) also reported similar results that CR increased gradually from the 1 st parity to the 4th parity and then decreased in the subsequent parities. Xu Fengxum (1997) observed higher $\mathrm{CR}$ in 1st, 2nd and 3rd parities than in later parities. Biochard and Manfredi (1994) reported that the CR in 1st parity of cows was highest (54\%) and the lowest in 7 th parity of cows $(38 \%)$. So, it may be concluded that the $\mathrm{CR}$ in zero to 3rd parity of cows are almost higher than that of subsequent parities. 

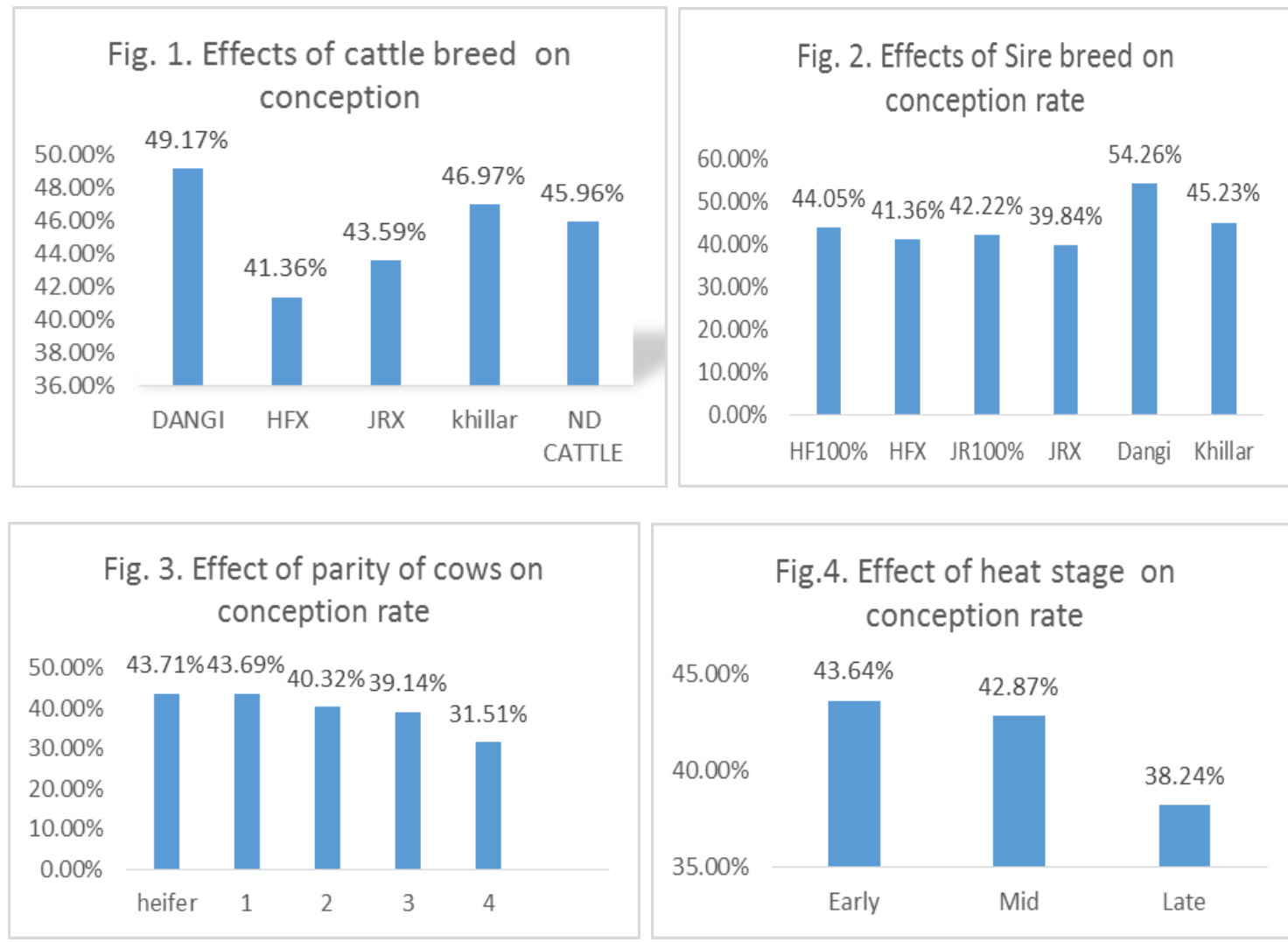
Fig.4. Effect of heat stage on conception rate
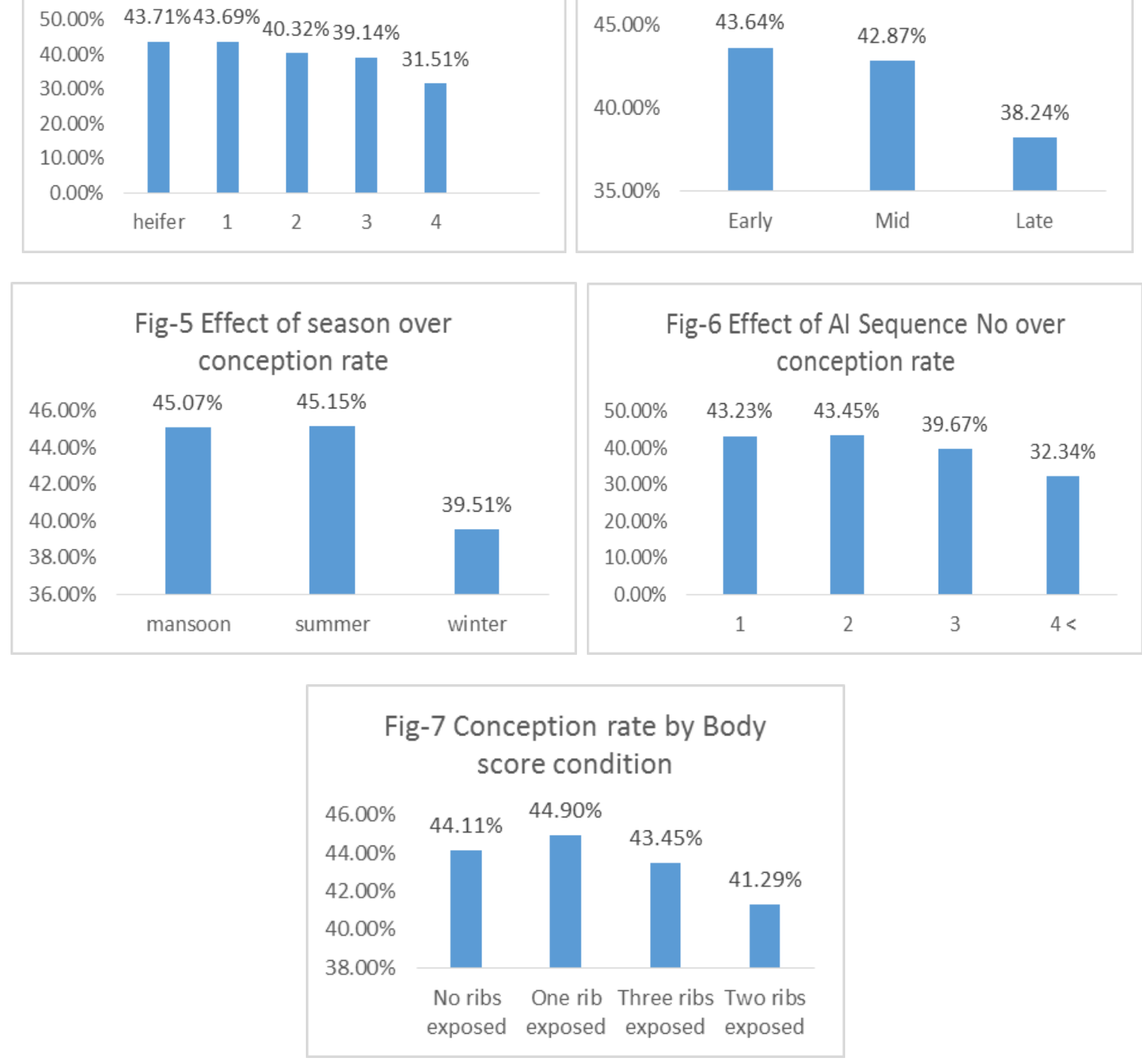

\section{Effect of heat stage}

There was significant difference effect due to heat stage of animal over conception rate. Heat stage is one of the most important factors influencing conception rate. From the study (Fig. 4), the highest conception rate was observed in early heat stage $(43.64 \%)$ than conception rate $(38.24 \%)$ when insemination was done in mid heat stage also clearly indicates the CR decreased in late heat stage (38.24\%) 


\section{Effect of season}

In this study, the conception rate was observed (Fig. 5) not significantly observed (P>0.05).Conception rate was higher $(45.15 \%)$ in the cows which were inseminated in summer than the cows were inseminated in monsoon (45.07\%) and winter (39.51\%). Alam and Ghosh (1988) reported that conception rate of the cows significantly differed in different seasons. Changes in nutrition, environmental temperature, and climate and photo period. The CR of cows markedly reduced when a higher temperature prevails for two days before insemination to 4-6 days after insemination (Gwazdauskas et al., 1975). Higher temperature and relative humidity (Zakari et al., 1981) and poor management affect on fertility of cattle. On the basis of all consideration, it may be concluded that monsoon is the best season for highest conception rate of cows having suitable ambient temperature and humidity.

\section{Effect of AI sequence number}

Sequence of A.I. had significant effect on conception rate it was observed that highest conception rate was recorded (Fig-6) in first and second attempt (43.23\%) \& (43.45\%) and after that it declines to $(39.67 \%) \&$ $(32.34 \%)$ in third and fourth attempt.

\section{Effect of body condition}

Study of body condition show no significant effect over conception rate study. Highest conception rate was observed (Fig-7) in animal with one rib exposed (44.90\%) with slightly lower in animal with no rib exposed $(44.11 \%)$. Conception rate in animal exposed three rib exposed was $(43.45 \%)$ while lowest conception rate was observed $(41.25 \%)$ in animal with two rib exposed.

\section{Discussion}

It was concluded from above investigation that for improvement in conception rate in rural cows, reproduction attributes like order of lactation, body condition of animal, sire breed, season, heat stage,AI sequence number these factors need to be considered.

\section{Acknowledgements:}

The authors are thankful to Management team of BAIF Development Research Foundation and all stakeholders in study area those who participated and cooperated during study.

\section{References}

[1]. Alam, M.G.S. and A. Ghosh, 1988. Reproductive performance in cows: its relation to parity and season. Bangladesh Vet. J., 22: 5161

[2]. Ball, L., 1980. Pregnancy diagnosis in cows. In: Morrow, D.A. (ed.). Current therapy in Theriogenology, 1st Ed., pp: 229-35. W.B. Saunders Co., Philadelphia, London, Toronto

[3]. Gwazdauskas, F.C., C.J. Wilcox and W.W. Thatcher, 1975. Environmental and managemental factors affecting conception rate in a subtropical climate. J. Dairy Sci., 58: 88-92

[4]. Marongiu, M.L., G. Molle, L. SanJuan, G. Bomboi, C. Ligios, A. Sanna, S. Casu and M.G. Diskin, 2002. Effects of feeding level before and after calving, and restricted suckling frequency on postpartum reproductive and productive performance of Sarda and Charolais $\times$ Sarda beef cows. Livestock Production Sci., 77: 2-3, 339-48

[5]. Morrow, D.A., 1980. Analysis of Record for Reproductive Herd Health Programs. In: Morrow, D.A. (ed.), Current Therapy in Theriogenology, 1st Ed., pp: 559-62. W.B. Saunders Co..Philadelphia, London, Toronto

[6]. Rao, A.V.M., M.S. Naidu and Y.N. Murthy, 1992. Effects of breed type of season on conception rates in cows. Wrld. Rev. Anim. Prod., 27: 3, 7, 23-25

[7]. Xu Fengxum, 1997. Conception rate of cows and analysis of its correlations. China Dairy Cattle, 4: 30-1

[8]. Zakari, A.Y., E.C.I. Molonkwu and D.I.K. Ossori, 1981. Effect of season on the estrus cycle of cows (Bos indicus) indigenous to Northern Nigeria. Vet. Rec., 109: 213-5 